\title{
On Uncertainty, Decision Values and Innovation
}

\author{
Sebastian Thöns ${ }^{1,2(凶)}$, Arifian Agusta $\operatorname{Irman}^{3}$, and Maria Pina Limongelli ${ }^{4}$ \\ ${ }^{1}$ Faculty of Engineering LTH, Lund University, Lund, Sweden \\ sebastian. thoensakstr.1th.se \\ 2 German Federal Institute for Materials Research and Testing, Berlin, Germany \\ ${ }^{3}$ Rambøll, Copenhagen, Denmark \\ ${ }^{4}$ Politechnico di Milano, Milan, Italy
}

\begin{abstract}
This paper contains a description, an alignment and a joint approach for technology readiness development with a three phases support of decision value analyses. The three phases are separated into the decision value forecasting, decision value analysis and the technology value quantification supporting the technological concept formulation and experimental testing, the prototype development and the technology qualification and operation. Decision value forecasting allows technology development guidance by technology performance requirements and the value creation even before the technology development is started. This approach is exemplified with load, damage and resistance information based integrity management of a structure and the ranking of the different strategies. The results can be used to guide a technology screening for matching with performance characteristics in terms of precision, cost and employability. Moreover, the first estimate of value creation of the technology for stakeholders, business models and market evaluation is provided.
\end{abstract}

Keywords: Innovation · Technology readiness · Decision analysis

\section{Introduction}

Decision theory has been introduced from economic sciences to built environment engineering by Benjamin and Cornell (1970) based on the works of Raiffa and Schlaifer (1961). In recent years, many studies have been published on topic of value quantification of structural health information (SHI) for built environment systems (e.g., Pozzi and Der Kiureghian (2011) and Thöns (2018)) also in conjunction with the COST Action TU1402 (www.cost-tu1402.eu and https://en.wikipedia.org/wiki/Value_of_structural_h ealth_information).

The SHI value quantification in the frame of the COST Action TU1402 has resulted in the scientific evidence of a high SHI value for built environment systems and its boundaries, an enhanced accessibility of the value of information analyses and guidelines for scientific utilisation, engineering and infrastructure owner usage. A scientific potential of guiding the technology development with a SHI value quantification has been identified. 
Technology readiness has been introduced by the USA National Aeronautics and Space Administration NASA (Sadin, Povinelli et al. (1989)) and has since penetrated technological management in various organisations such as e.g. military organisations and the European Space Agency ESA. Technology readiness levels have been defined for the European research and innovation program Horizon 2020 since 2009 (see e.g., Héder (2017)).

The technology development is subdivided in a stepwise technology readiness process starting with the observation, concept formulation and experimental testing and (Technology Readiness Levels - TRLs 1 to 4) followed by technology demonstration and prototype development (TRLs 5 to 7 ) and the technology qualification and operation (TRL 8 and 9), see e.g. Héder (2017) and Table 1.

Table 1. European Technology Readiness Levels according to Héder (2017)

\begin{tabular}{l|l}
\hline TRL 1 & Basic principles observed \\
\hline TRL 2 & Technology concept formulated \\
\hline TRL 3 & Experimental proof of concept \\
\hline TRL 4 & Technology validated in lab \\
\hline TRL 5 & Technology validated in relevant environment \\
\hline TRL 6 & Technology demonstrated in relevant environment \\
\hline TRL 7 & System prototype demonstration in operational environment \\
\hline TRL 8 & System complete and qualified \\
\hline TRL 9 & Actual system proven in operational environment \\
\hline
\end{tabular}

A technology development has the potential for innovation and innovation scaling when the technology performs and creates value for market stakeholders as a premise for the development of a new market according to the Disruptive Innovation Theory (e.g. Bower and Christensen (1995) and Christensen (1997)). However, the TRL development accounts solely for technological steps and not for technology value quantification.

This paper focuses on the utilisation of decision theory - originating from the field of economic management science - along the technology development for information acquirement system innovation guidance. The paper starts out with summarising the decision analytical formulation for built environment systems and how a value quantification is performed (Sect. 2). An approach to align the technology development with different types of decision analyses is developed in Sect. 3. The first step of this approach namely decision value forecasting is described and exemplified in Sect. 4. The paper closes with a summary and conclusions highlighting the potential for innovation guidance and pointing to further research. 


\section{Decision Analytical Formulation}

Decision analyses encompass the modelling of built environment systems, information about the system performance and actions to modify the system states or system performance.

System models are used to assess and predict the behaviour of real-world systems subjected to exposures and disturbances, which influence the component and the system states. Information is based on observations of the physical world from which data can be extracted, indicators for evaluating the system states and performance can be derived and information to adapt and update the system states and system performance can be obtained. Information in turn facilitates closer to reality predictions of the system performance and implies that the adaptation with information is solely on the side of the models and will not affect the real-word system performance.

An action - as a physical system change - influences the physical world system performance and the modelled system performance. In this sense, actions can be used for enforcing a coherence of the modelled system performance and the physical world system performance. For planning of actions, an enhanced system knowledge by adaption with information may be used.

The information $i_{i}$ supported decision analytical formulation for built environment systems consists of models for the information and integrity management and for the system performance composed of system states $X_{l}$ and associated utilities $u(\ldots)$. It is distinguished between probabilistic models for information outcomes $Z_{i, j}$ and system states and decision variables relating to information and actions $a_{k}$ (Fig. 1).

Following Benjamin and Cornell (1970), the decision analytical objective functions are formulated for a prior analysis without additional information, a posterior analysis with known additional information and a pre-posterior analysis with predicted information. In a prior and posterior decision analysis, the actions constitute the decision variables maximizing the prior or posterior expected utilities $\left(U_{\text {prior }}\right.$ and $U_{\text {Post }}$, respectively) based on the expected utility theorem, see e.g. Von Neumann and Morgenstern (1947). A pre-posterior decision analysis facilitates to optimise the expected value of the utility also by the choice of the information acquirement strategy (with the index $i$ ).

The expected value of the utility does not constitute per se a value. Only in relation to a threshold, a value can be quantified as described in Raiffa and Schlaifer (1961) by interrelating decision theory to economical concepts. Following the original formulation, the value of information has been quantified as the difference of the expected utilities stemming from a decision analysis without and with information constituting the base the and the enhancement scenario. This original formulation is extended here with varying the base and enhancement scenarios for more comprehensiveness (Thöns and Kapoor (2019)).

The value of a predicted action can be quantified by subtracting the expected system performance utility without or with an implemented action, $U_{S P}$ and $U_{S P}(a)$, respectively, from an expected system performance utility with a predicted action $U_{\text {Prior }}$, see Eq. (1). When the optimal action (sets) $a_{1}$ and $a_{2}$ are not identical, then the action (set) value in relation to another action (set) can be quantified as the difference between two prior decision analyses, $U_{\text {Prior }}\left(a_{k_{1}}\right)$ and $U_{\text {Prior }}\left(a_{k_{2}}\right)$, see Eq. (2). The value contains the action costs and consequences. 


\begin{tabular}{|c|c|c|c|c|c|}
\hline \multicolumn{3}{|c|}{$\begin{array}{l}\text { Information and integrity } \\
\text { management }\end{array}$} & \multirow[t]{2}{*}{ System } & \multirow[t]{2}{*}{ Utility } & \multirow{2}{*}{$\begin{array}{l}\text { Objective function } \\
\qquad U_{S P}=E_{X_{l}}\left[u\left(X_{l}\right)\right]=\sum_{X_{I}} u\left(X_{l}\right) \cdot P\left(X_{l}\right)\end{array}$} \\
\hline Choice & Chance & Choice & & & \\
\hline \multicolumn{3}{|c|}{ Action implemented } & & & $U_{S P}(a)=E_{X_{l}}\left[u\left(a, X_{l}\right)\right]=\sum_{X_{l}} u\left(a, X_{l}\right) \cdot P\left(X_{l}\right)$ \\
\hline \multicolumn{3}{|c|}{ Action predicted } & & $\nabla$ & $\begin{aligned} U_{\text {Prior }} & =\max _{a_{k}} E_{X_{l}}\left[u\left(a_{k}, X_{l}\right)\right] \\
& =\max _{a_{k}} \sum_{X_{l}} u\left(a_{k}, X_{l}\right) \cdot P\left(X_{l}\right)\end{aligned}$ \\
\hline \multicolumn{2}{|c|}{ Information obtained } & & & $>$ & $\begin{aligned} U_{\text {Post }}(Z) & =\max _{a_{k}} E_{X_{l} \mid Z}\left[u\left(Z, a_{k}, X_{l}\right)\right] \\
& =\max _{a_{k}} \sum_{X_{l}} u\left(Z, a_{k}, X_{l}\right) \cdot P\left(X_{l} \mid Z\right)\end{aligned}$ \\
\hline \multicolumn{3}{|c|}{ Information predicted } & & $r$ & \multirow[t]{2}{*}{$\begin{array}{l}U_{\text {PrePost }}=\max _{i_{i}} E_{Z_{i, j}}\left[\max _{a_{k}} E_{X_{l} \mid Z_{i, j}}\left[u\left(i_{i}, a_{k}, X_{l}\right)\right]\right] \\
\quad=\max _{i_{i}} \sum_{Z_{i, j}} P\left(Z_{i, j}\right) \cdot \max _{a_{k}} \sum_{X_{l} \mid Z_{i, j}} u\left(i_{i}, a_{k}, X_{l}\right) \cdot P\left(X_{l} \mid Z_{i, j}\right)\end{array}$} \\
\hline $\begin{array}{l}\text { Informatic } \\
i_{i}\end{array}$ & $\begin{array}{l}\text { Outcomes } \\
Z_{i, j}\end{array}$ & $\begin{array}{l}\text { Actions } \\
a_{k}\end{array}$ & $\begin{array}{l}\text { System states } \\
X_{l}\end{array}$ & $\begin{array}{l}\text { Utility } \\
u\end{array}$ & \\
\hline
\end{tabular}

Fig. 1. Decision analytical formulation for quantification of the expected utilities by a system performance analysis $\left(U_{S P}\right)$, a prior decision analysis $\left(U_{\text {Prior }}\right)$, a posterior decision analysis $\left(U_{\text {Post }}\right)$ and a pre-posterior decision analysis ( $\left.U_{\text {PrePost }}\right)$.

$$
\begin{gathered}
V_{S P}^{\text {Prior }}\left(a_{k}\right)=U_{\text {Prior }}-U_{S P} \text { and } V_{S P}^{\text {Prior }}\left(a_{k}, a\right)=U_{\text {Prior }}-U_{S P}(a) \\
V_{\text {Prior }, a_{k_{2}}}^{\text {Prior } a_{k_{1}}}\left(a_{k_{1}}, a_{k_{2}}\right)=U_{\text {Prior }}\left(a_{k_{1}}\right)-U_{\text {Prior }}\left(a_{k_{2}}\right)
\end{gathered}
$$

The predicted value of an information can be quantified in analogy to the action value as the expected utility difference with an enhancement scenario containing predicted, i.e. pre-posterior, information and a base scenario excluding this predicted information. The base scenario can be of the types of a prior, a posterior and a pre-posterior decision analysis. For the latter, the information acquirement strategy sets $i_{1}$ and $i_{2}$ are exclusive. The value contains the information costs:

$$
\begin{aligned}
V_{\text {Prior }}^{\text {PrePost }}\left(i_{i}\right)= & U_{\text {PrePost }}-U_{\text {Prior }} \text { and } V_{\text {Post }}^{\text {PrePost }}\left(i_{i}, Z\right)=U_{\text {PrePost }}-U_{\text {Post }}(Z) \\
& V_{\text {PrePost }, i_{2}}^{\text {PrePost }, i_{1}}\left(i_{1}, i_{2}\right)=U_{\text {PrePost }}\left(i_{1}\right)-U_{\text {PrePost }}\left(i_{2}\right)
\end{aligned}
$$

The value of information and actions can be quantified by using the base scenarios of the action value quantification and the enhancements scenarios of the information value quantification. Both, the information costs and the action costs and consequences are included in the value quantification:

$$
V_{S P}^{\text {PrePost }}\left(i_{i}, a_{k}\right)=U_{\text {PrePost }}-U_{S P} \text { and } V_{S P}^{\text {PrePost }}\left(i_{i}, a\right)=U_{\text {PrePost }}-U_{S P}(a)
$$




$$
V_{\text {PrePost }, 2}^{\text {PrePost } 1}\left(i_{1}, i_{2}, a_{k_{1}}, a_{k_{2}}\right)=U_{\text {PrePost }}\left(i_{2}, a_{k_{2}}\right)-U_{\text {Prior }}\left(i_{1}, a_{k_{1}}\right)
$$

The decision value can be divided with the expected utility of the base scenario resulting in a normalised decision value $\bar{V}$.

\section{Decision Value and Technology Readiness}

Three types of decision value analyses are distinguished namely (1) value forecasting, (2) value analysis and (3) technology value quantification, which are temporally aligned with the technology development phases (Fig. 2). The decision value forecasting analysis is performed solely with a probabilistic built environment system performance analysis and the consideration of a base scenario constituting the conventional and known technology. The information and action modelling exploits characteristics of the built environment system performance model.

The decision value analysis is performed with a probabilistic and experimentally verified technology performance for (a) the quantification of the current decision value and (b) potentials for decision value optimisation and (c) boundaries for optimality such as e.g. decision rules.

The technology value quantification constitutes a decision value analysis in the operational environment and with consideration of technology production boundaries. For the stages of a decision value analysis and the technology value quantification there are many studies such as e.g. Thöns (2018), Long, Döhler et al. (2020) and Thöns and Stewart (2020).

\begin{tabular}{|c|c|c|}
\hline DVA Type & & Technology readiness development \\
\hline $\begin{array}{l}\text { Value forecasting } \\
\text { - Utility scenario identification and modelling } \\
\text { - Establishment of a base scenario incorporating }\end{array}$ & $\begin{array}{l}\text { Technology and research } \\
\text { screening }\end{array}$ & $\begin{array}{l}\text { TRL } 1 \text { - Basic principles observed } \\
\text { TRL } 2 \text { - Technology concept formulated }\end{array}$ \\
\hline $\begin{array}{l}\text { - Identification of technology performance } \\
\text { requirements }\end{array}$ & $\begin{array}{l}\text { Proof and of validation of } \\
\text { performance requirements }\end{array}$ & $\begin{array}{l}\text { TRL } 3 \text { - Experimental proof of concept } \\
\text { TRL } 4 \text { - Technology validated in lab }\end{array}$ \\
\hline $\begin{array}{l}\text { Value analysis } \\
\text { - Probabilistic technology modelling } \\
\text { - Identification of boundaries and optimal } \\
\text { technology performance parameters }\end{array}$ & $\begin{array}{l}\begin{array}{l}\text { Determination of technology } \\
\text { performance parameters }\end{array} \\
\begin{array}{l}\text { Performance parameter } \\
\text { optimisation }\end{array}\end{array}$ & $\begin{array}{l}\text { TRL } 5 \text { - Technology validated in relevant } \\
\text { environment } \\
\text { TRL } 6 \text { - Technology demonstrated in relevant } \\
\text { environment }\end{array}$ \\
\hline $\begin{array}{l}\text { Technology value quantification } \\
\text { - Optimisation for technology value in operational } \\
\text { environment } \\
\text { - Accounting for operational boundaries }\end{array}$ & $\begin{array}{l}\text { Technology employment } \\
\text { optimisation }\end{array}$ & $\begin{array}{l}\text { TRL } 7 \text { - System prototype demonstration in } \\
\text { operational environment } \\
\text { TRL } 8 \text { - System complete and qualified } \\
\text { TRL } 9 \text { - Actual system proven in operational } \\
\text { environment }\end{array}$ \\
\hline
\end{tabular}

Fig. 2. Decision value analyses and technology readiness. 
In relation to the TRLs 1 and 2, the decision value forecasting phase is temporally located before the technology development starts. With a base scenario and the utility scenario modelling as well as the identification of technology performance requirements, a basic principle and conceptual technology screening can be performed. With experimental proof and validation, the technology performance parameters (at TRLs 3 and 4) can be validated against the performance requirements for the desired decision value.

Further experimental testing in a relevant environment (TRLs 5 and 6) will improve the performance parameter optimisation and development of probabilistic technology performance models to be integrated in a decision value analysis. The decision value analysis will reveal conditions and potentials for utility gains, which can be used as an input for the further technology development. A technology value quantification is performed to fully represent the technology performance in an operational environment. The technology value quantification can be performed with different base scenarios constituting different conventional technology approaches.

\section{Decision Value Forecasting}

The described decision value forecasting approach is introduced. For this purpose, a decision scenario is formulated consisting of a built environment system performance model for which information acquirement technology is to be developed facilitating an efficient information and integrity management.

The information value forecasting is developed with a built environment system performance model distinguishing the complementary intact $\left(X_{1}=S\right)$ and failure state $\left(X_{2}=F\right)$ with the limit state function (7), $g_{F}$. The resistance $R$, the damage $D$ (with its capacity transformation function $t_{D}$ ) and the loading $S$ are based on models, for which the precision is known with the respective model uncertainties $M$. The limit state equation is representative for a non-redundant built environment system subjected to a dominating failure mode under deterioration (JCSS (2001-2015)).

$$
X_{1}=S: \quad g_{F}=M_{R} \cdot R\left(1-t_{D} \cdot M_{D} \cdot D\right)-M_{S} \cdot S>0, \quad X_{2}=F: \quad g_{F} \leq 0
$$

The consequences of the intact and failure state are modelled to calculate the expected value of the utility with a system performance (SP) analysis.

Information in its fundamental meaning is about the knowledge of system states (see Raiffa and Schlaifer (1961)). Progressing this fundamental concept, the limit state model as introduced with Eq. (7) and the fact that information can be forecasted with the help of realisations of the model uncertainties is applied (see e.g. Thöns (2018)). By introducing model uncertainty realisation thresholds $\eta$, indication events can be discretised (see Eq. (8) with one threshold and two complementary indication events for use in conjunction with Eq. (7)). The thresholds can be defined and/or optimised for system performance in relation to availability, failure and/or utility probabilities (see Agusta (2020)).

$$
Z_{i, 1}: P\left(Z_{i, 1}\right)=\int_{-\infty}^{\eta} f_{M}(m) d m ; \quad Z_{i, 2}: P\left(Z_{i, 2}\right)=\int_{\eta}^{\infty} f_{M}(m) d m
$$


The pre-posterior and the posterior probabilities of the system states are calculated with the truncated and normalised or just truncated model uncertainty distributions $f_{\left.M\right|_{-\infty} t_{M}}$ and $f_{\left.M\right|_{t_{M}}}$, respectively. Additionally, the random variable $M_{U}$ can be multiplied to the respective model uncertainty to account for a limited precision of the information.

Actions can be introduced as engineering actions and/or utility actions modifying the system state probabilities and/or the system state utilities, respectively.

\subsection{Exemplary Study of Decision Value Forecasting}

The decision value forecasting approach takes basis in the system state Eq. (7), which is representative for a built environment system subjected to a dominating failure mode under deterioration (JCSS (2001-2015), Fig. 3). The resistance is without damage and in analogy to a structural design process calibrated to a target failure probability of $P_{T}=10^{-5}$. Such target represents a the reliability of typical engineering structure subjected to moderate consequences of failure and normal costs of safety measures (see e.g. ISO 2394 (2015)). The model uncertainties are adjusted in conjunction with Part 3.09 of the Probabilistic Model Code of the Joint Committee on Structural Safety (JCSS (2001-2015)) with higher model uncertainties for the loading and the damages. Failure consequence, i.e. a negative utility $u(F)$, is normalised. A utility $u(S \mid m)$ for a possible service life extension is assigned in case the structural reliability is high due to compliance with the threshold $\eta_{1}$ and its calibration to a target reliability.

\begin{tabular}{|c|c|c|c|}
\hline Variable & $\begin{array}{c}\text { Distributio } \\
\mathrm{n}\end{array}$ & Expected Value & St. dev. \\
\hline$S$ & Weibull & 3.5 & 0.10 \\
\hline$R$ & Lognormal & $P(F \mid D=0.0)=P_{T}$ & 0.10 \\
\hline$D$ & Normal & 2.0 & 0.10 \\
\hline$t_{D}$ & Det. & 0.1 & - \\
\hline$M_{R}$ & Lognormal & 1.0 & 0.05 \\
\hline$M_{S}$ & Lognormal & 1.0 & 0.10 \\
\hline$M_{D}$ & Lognormal & 1.0 & 0.20 \\
\hline$P_{T}$ & Det. & $10^{-5}$ & - \\
\hline $\begin{array}{c}u\left(S \mid m_{S} \leq \eta_{1}\right) \text { or } \\
u\left(S \mid m_{D} \leq \eta_{1}\right) \text { or } \\
u\left(S \mid m_{R} \geq \eta_{1}\right)\end{array}$ & Det. & 0.001 & - \\
\hline$u(F)$ & Det. & -1.0 & - \\
\hline
\end{tabular}

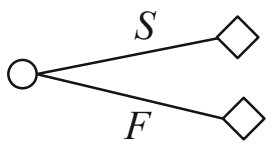

Fig. 3. System performance model (Eq. (7)) and part of decision tree (see Fig. 1)

Information is modelled by exploiting the characteristics of model uncertainties namely that the system state behaviour of a constructed built environment system represents a realisation of the model uncertainty (Thöns (2018), Agusta and Thöns (2018)). 
The model uncertainty thresholds are introduced for a higher or equal (target) failure probability than required, $\eta_{1}$, and for the optimal action being repair, $\eta_{2}$. In this way the thresholds are optimised to comply with the decision rules $r(\ldots)$ of repairing (denoted with $a_{1}$ ) only for a $Z_{i, 3}$ indication informing low structural reliability (Eq. (9)). The indication $Z_{i, 1}$ informs about a high reliability, the indication $Z_{i, 2}$ of a reliability as expected:

$$
r\left[Z_{i, 1}, Z_{i, 2}, Z_{i, 3}\right]=\left[a_{0}, a_{0}, a_{1}\right]
$$

Equation (10) shows the probabilities of indications calculation for the discretisation of the load model uncertainties. Note that the discretisation for the resistance model uncertainty requires a different order of the integration boundaries in conjunction with the threshold determination rules in Figs. 3 and 4.

The information may be subjected to a finite precision expressed with a generic, Normal distributed information uncertainty $M_{U}$ with a coefficient of variation of $5 \%$ (Fig. 4). The information has a cost of $c\left(i_{i}\right)=0.0015$ adjusted to similar consequence and cost ratios in e.g. Thöns (2018).

$$
P\left(Z_{1,1}\right)=\int_{-\infty}^{\eta_{1}} f_{M_{S}}\left(m_{S}\right) d m_{S} ; P\left(Z_{1,2}\right)=\int_{\eta_{1}}^{\eta_{2}} f_{M_{S}}\left(m_{S}\right) d m_{S} ; P\left(Z_{1,3}\right)=\int_{\eta_{2}}^{\infty} f_{M_{S}}\left(m_{S}\right) d m_{S}
$$

The repair action will lead to damage of zero, $D\left(a_{1}\right)=0.0$, and costs of $c\left(a_{1}\right)=0.01$ see e.g. Thöns (2018).

\begin{tabular}{|c|c|c|c|}
\hline Variable & Distribution & Expected Value & St. dev. \\
\hline$D\left(a_{1}\right)$ & Det. & 0.0 & - \\
\hline$c\left(a_{1}\right)$ & Det. & 0.01 & - \\
\hline$M_{U}$ & Normal & 1.0 & 0.05 \\
\hline$c\left(i_{i}\right)$ & Det. & 0.0015 & - \\
\hline$\eta_{1}$ & Det. & $P\left(F \mid m=\eta_{1}\right)=P_{T}$ & - \\
\hline$\eta_{2}$ & Det. & $a_{\text {opt }}=a_{1}$ & - \\
\hline
\end{tabular}

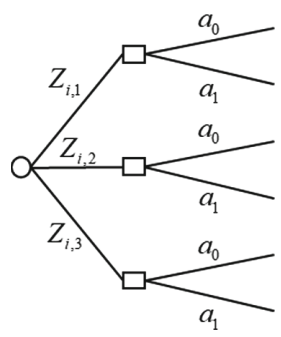

Fig. 4. Information and integrity management model and part of decision tree (see Fig. 1)

The information and integrity management model will be used to predict and to preposteriorly and posteriorly update the probabilities of failure and survival. For example, the posteriorly updated probability of failure with a $Z_{1,1}$ indication subjected to the information uncertainty $M_{U}$ is calculated with the threshold-truncated and normalised distribution $\left.M_{S}\right|_{-\infty} ^{\eta_{1}}$ :

$$
F\left|Z_{1,1}: \quad g_{F \mid Z_{1,1}}=M_{R} \cdot R\left(1-t_{D} \cdot M_{D} \cdot D\right)-M_{U} \cdot M_{S}\right|_{-\infty}^{\eta_{1}} \cdot S \leq 0
$$

With the decision value analysis, the indication dependent posterior values and the probabilities of the information and integrity management strategies are forecasted. For 
information about the load, both the $Z_{1,1}$ and $Z_{1,2}$ indication, denoting a behaviour better or as expected, respectively, lead to a positive posterior decision value (Fig. 5). The $Z_{1,3}$ indication requires a repair (see decision rules in Eq. (9)) and leads to a negative value. The indication $Z_{1,2}$ has a significantly higher probability than the other indications. The influence of the information precision is not very pronounced as only the $Z_{1,1}$ and $Z_{1,2}$ probabilities and the $Z_{1,2}$ posterior value are slightly influenced.

For resistance information, the most probable $Z_{2,2}$ indication lead to low or even negative posterior relative decision value with consideration of the information precision. The low probability indication $Z_{2,1}$ leads to high decision value. The influence of the information uncertainty is rather pronounced affecting the probabilities of the indications $Z_{2,2}$ and $Z_{2,3}$.
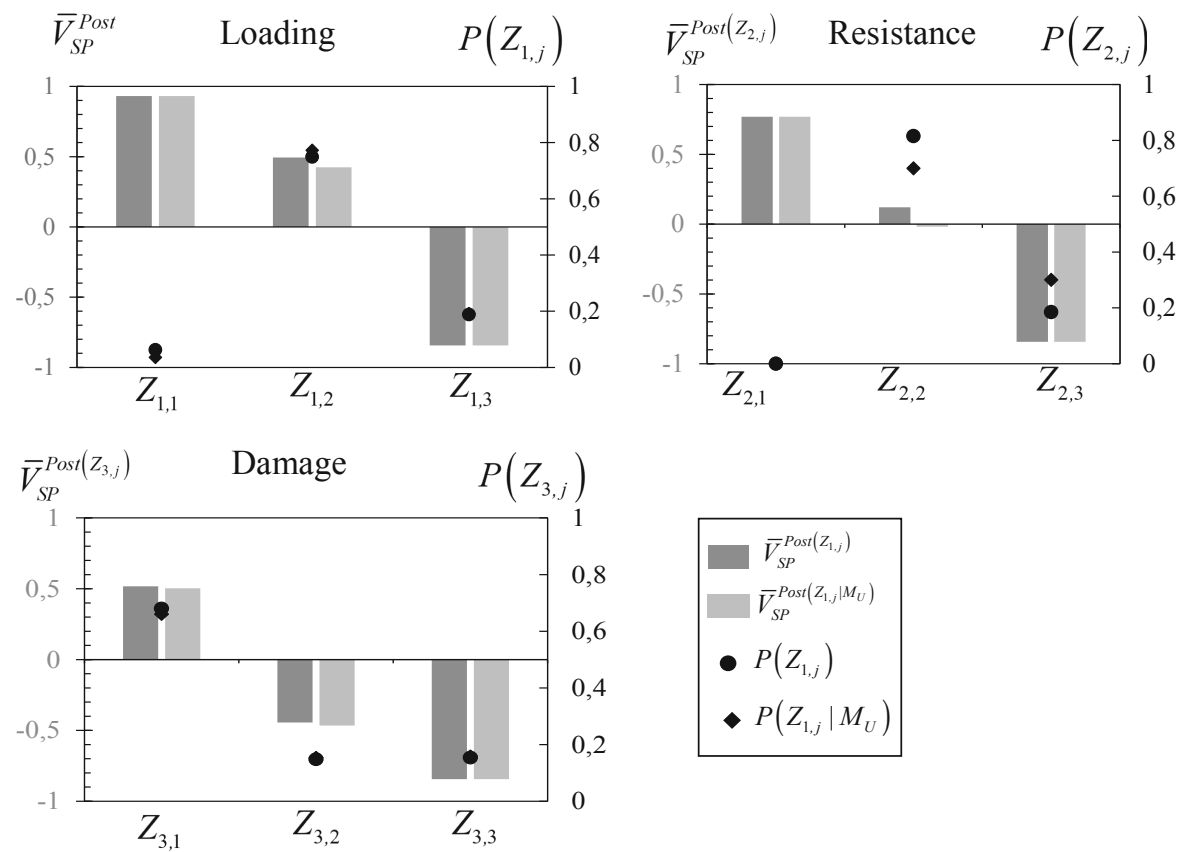

Fig. 5. Posterior decision value of information and integrity management and perfect and imperfect indication probabilities for loading, resistance and damage information

For damage information, the indication $Z_{3,1}$ has the highest probability followed by approximately equal probabilities of the $Z_{3,2}$ and $Z_{3,3}$ indications. The information uncertainty has minor influence both on the indication probabilities and the values.

The pre-posterior, i.e. the predicted, value of information and integrity management has been calculated by summing the product of the indication probabilities and the posterior values (Table 2). Positive values are calculated for load and damage information with and without consideration of the information precision. The information precision significantly influences the value of the integrity management with load information. 
The damage information value is less influenced, which is attributed to the damageresistance transfer function. The influence of the information precision is lower for the integrity management with damage information. Resistance information do not lead to a positive value.

The decision value between the strategies $\bar{V}_{\text {PrePost, }, 1}^{\text {Prest } 2}$ is quantified with the load information strategy (Table 2) as a basis. Damage information and with consideration of its uncertainties leads to the highest value $\bar{V}_{\text {PrePost, }}^{\text {PrePt }}$ explicitly quantifying the second best alternative in the ranking of the information and integrity management strategies.

Table 2. Thresholds and pre-posterior value of information

\begin{tabular}{|c|c|c|c|c|c|}
\hline \multirow[t]{2}{*}{ Strategy } & \multirow[t]{2}{*}{ Description } & \multicolumn{2}{|c|}{ Thresholds } & \multirow[t]{2}{*}{$\bar{V}_{\mathrm{SP}}^{\text {PrePost }}$} & \multirow{2}{*}{$\bar{V}_{\text {PrePost }, 1}^{\text {PrePost }, 2}$} \\
\hline & & $\eta_{1}$ & $\eta_{2}$ & & \\
\hline \multicolumn{6}{|c|}{ Perfect Information (PI) } \\
\hline 1 & Load & 0.84 & 1.11 & 0.32 & - \\
\hline 2 & Resistance & 1.29 & 0.95 & -0.05 & -0.37 \\
\hline 3 & Damage & 1.09 & 1.20 & 0.16 & -0.16 \\
\hline \multicolumn{6}{|c|}{ Imperfect Information (II) } \\
\hline 1 & Load & 0.83 & 1.09 & 0.18 & - \\
\hline 2 & Resistance & 1.31 & 0.97 & -0.29 & -0.47 \\
\hline 3 & Damage & 1.08 & 1.19 & 0.13 & -0.05 \\
\hline
\end{tabular}

\section{Summary and Conclusions}

This paper contains a description, an alignment and a joint approach for technology readiness development with a three phases support by decision value analyses. The decision value analyse are divided into the decision value forecasting, value decision value analysis and the technology value quantification phases. The technology readiness development levels (TRLs) are seperated into technological concept formulation and experimental testing (TRLs 1 to 4), the prototype development (TRLs 5 to 7) and the technology qualification and operation (TRLs 8 and 9).

The decision value forecasting approach relies solely on a built environment system performance model. Decision value forecasting facilitates support for the first phases of technology readiness development, i.e. for technological concept formulation and experimental testing. With an exemplary decision value forecasting analysis, it was found that for a built environment system, load or damage information acquirement systems with a high precision should be developed. Resistance information acquirement system should not be developed as the forecasted decision value is negative. In the context of business model and technology markets, a forecast of the achievable technology value for the structural information and integrity management has been provided in the order of $13 \%$ to $32 \%$. 
The alignment of technology development, innovation and decision value analyses requires more systematic research and applications to substantiate and detail their interrelations and to demonstrate the targeted support of innovation decisions with case studies.

The approach has been written in the context of technology development, which may, however, be composed of a technological and algorithmic readiness level development (see e.g. Limongelli, Orcesi et al. (2018)).

\section{References}

Agusta, A.: Structural Integrity and Risk Management based on Value of Information and Action Analysis. Ph.D. thesis (2020)

Agusta, A., Thöns, S.: Structural monitoring and inspection modeling for structural system updating. In: Sixth International Symposium on Life-Cycle Civil Engineering (IALCCE), Ghent, Belgium, 28-31 October 2018 (2018)

Benjamin, J.R., Cornell, C.A.: Probability, Statistics and Decision for Civil Engineers. McGrawHill, New York (1970). ISBN: 070045496

Bower, J.L., Christensen, C.M.: Disruptive technologies: catching the wave. Harv. Bus. Rev. 73(1), 43-53 (1995)

Christensen, C.M.: The Innovator's Dilemma: When New Technologies Cause Great Firms to Fail, University of Illinois at Urbana-Champaign's Academy for Entrepreneurial Leadership (1997)

Héder, M.: From NASA to EU: the evolution of the TRL scale in public sector innovation. Innov. J. 22(2), 1-23 (2017)

ISO 2394: General Principles on Reliability for Structures ISO 2394 (2015)

JCSS: Probabilistic Model Code, JCSS Joint Committee on Structural Safety. ISBN: 978-3909386-79-6 (2001-2015)

Limongelli, M.P., Orcesi, A., Vidovic, A.: The indicator readiness level for the classification of research performance indicators for road bridges. In: The Sixth International Symposium on Life-Cycle Civil Engineering, IALCCE 2018 GHENT, Ghent University, Belgium (2018)

Long, L., Döhler, M., Thöns, S.: Determination of structural and damage detection system influencing parameters on the value of information. Struct. Heal. Monitor. (2020). https://doi.org/ $10.1177 / 1475921719900918$

Pozzi, M., Der Kiureghian, A.: Assessing the value of information for long-term structural health monitoring. In: Health Monitoring of Structural and Biological Systems 2011, San Diego, California, United States, 7-10 March 2011 (2011)

Raiffa, H., Schlaifer, R.: Applied Statistical Decision Theory. New York, Wiley (2000). ISBN: 047138349X (1961)

Sadin, S.R., Povinelli, F.P., Rosen, R.: The NASA technology push towards future space mission systems. Acta Astronautica 20(C), 73-77 (1989). https://doi.org/10.1016/0094-5765(89)900 54-4

Thöns, S.: On the value of monitoring information for the structural integrity and risk management. Comput.-Aid. Civil Infrastruct. Eng. 33(1), 79-94 (2018). https://doi.org/10.1111/mice.12332

Thöns, S., Kapoor, M.: Value of information and value of decisions. In: 13th International Conference on Applications of Statistics and Probability in Civil Engineering (ICASP), Seoul, Korea, 26-30 May 2019

Thöns, S., Stewart, M.G.: On the cost-efficiency, significance and effectiveness of terrorism risk reduction strategies for buildings. Struct. Saf. 85, (2020). https://doi.org/10.1016/j.strusafe. 2020.101957

Neumann, V., Morgenstern, O.: Theory of Games and Economical Behavior. Princeton University Press, Princeton (1947) 
Open Access This chapter is licensed under the terms of the Creative Commons Attribution 4.0 International License (http://creativecommons.org/licenses/by/4.0/), which permits use, sharing, adaptation, distribution and reproduction in any medium or format, as long as you give appropriate credit to the original author(s) and the source, provide a link to the Creative Commons license and indicate if changes were made.

The images or other third party material in this chapter are included in the chapter's Creative Commons license, unless indicated otherwise in a credit line to the material. If material is not included in the chapter's Creative Commons license and your intended use is not permitted by statutory regulation or exceeds the permitted use, you will need to obtain permission directly from the copyright holder.

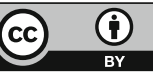

